\title{
Organizational Hiring Practices Of Persons With Disabilities: A Study And Review Of Corporations, Small Businesses, Non-Profit Organizations, Foundations, And The US Government
}

Nancy A. Maier, University of Detroit Mercy, USA

Gregory W. Ulferts, University of Detroit Mercy, USA

Terry L. Howard, University of Detroit Mercy, USA

\begin{abstract}
This paper presents findings from research conducted to identify organizational hiring practices of people with disabilities. Despite the passage of the American with Disabilities Act in 1990, employment rates for people with disabilities remain far lower than for people of any other minority group. Further, this paper will offer best practices in hiring people with disabilities and resources available through federal, state and private sectors.
\end{abstract}

Keywords: Hiring Practices of Persons with Disabilities; American with Disabilities Act

THE US GOVERNMENT AND THE LAW

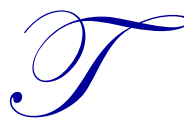

here are several areas of the US government that have oversight and provide regulation for the hiring practices and protection of people with disabilities. Following are just two areas within the Federal Government with responsibilities in this area:

1. The Department of Labor's Office of Disability Employment Policy (ODEP) provides publications and other technical assistance on the requirements of the ADA, but it does not enforce any part of the law. Other federal laws bar discrimination on the basis of disability in employment and are either enforced or administered by the Department of Labor. The primary law is Section 503 of the Rehabilitation Act of 1973, which requires federal contractors and subcontractors with government contracts in excess of $\$ 10,000$ to take affirmative action to employ and advance in employment qualified individuals with disabilities. The Office of Federal Contract Compliance Programs (OFCCP) is responsible for enforcing Section 503.

2. The Department's Civil Rights Center (CRC) enforces the employment-related provisions of Section 504 of the Rehabilitation Act. Section 504 covers organizations and entities that receive federal financial assistance from DOL. CRC also enforces Title II of the ADA as that title applies to the labor- and workforce-related practices of state and local governments and other public entities. Finally, CRC enforces Section 188 of the Workforce Investment Act of 1998 (WIA), which bars disability-based discrimination by programs and activities that are part of the One-Stop employment and training system established by WIA Title I.

According to the 2000 U.S. Census, one in five Americans has a disability. As the population ages, this number is predicted to grow. We recognize people with disabilities when we see a wheelchair, a cane, a service animal, or a person using sign language. We do not necessarily recognize people with invisible disabilities, 
including people with epilepsy, traumatic brain injury, mental health conditions, arthritis, diabetes, learning disabilities, or other disabilities. This very common discrepancy in thought process about people with disabilities could possibly be a major hindrance in organizational hiring practices. Even with specific laws in place and governmental offices monitoring and regulating hiring practices, progress in this area has been stagnant.

As an example, unemployment in the United States reached a thirty-year low by the end of 2000; those who wanted to work could find employment. Some employers had difficulties finding good employees and, at times, resorted to partnering with local prisons to hire prisoners. People with disabilities were then, and still are, experiencing unemployment at a rate far above the national average.

In 2010, the 20th anniversary of the signing of the Americans with Disabilities Act, people with disabilities were still facing the same lifestyle and economic challenges they confronted in 1990 . According to a 2010 survey sponsored by Kessler Foundation and the National Organization on Disability (NOD) and conducted by Harris Interactive, there has been little to no substantial gains in ten key indicators: 1) employment, 2) income, 3) education, 4) health care, 5) access to transportation, 6) socializing, 7) going to restaurants, 8) attendance at religious services, 9) political participation, and 10) life satisfaction.

The largest gap between people with and without disabilities exists in the area of employment, a discrepancy the survey attributes to the ongoing lack of progress in areas such as income, access to health care, and socialization. Among all working-age people with disabilities, only 21 percent say they are employed full or part time, compared to 59 percent of people without disabilities - a gap of 38 points.

Given the disparity in numbers of hiring, there are many reasons to hire people with disabilities, such as:

- $\quad$ People with disabilities represent an available trained labor supply.

- $\quad$ Economic incentives make hiring people with disabilities an effective, cost-based decision.

- The Americans with Disabilities Act and other legislation prohibit discrimination against qualified people with disabilities.

- $\quad$ Hiring and promoting people with disabilities are good for public relations; it can enhance the reputation of organizations with their stakeholders.

- $\quad$ Hiring qualified people with disabilities conveys a sense of social responsibility.

\section{BEST PRACTICES}

Although hiring of people with disabilities remains a challenge in the American work force, there is evidence that state governments are leading the way in best practices for hiring those with disabilities. With more than five million workers nationwide and the unique opportunities to serve as model employers, state governments can play a significant role in enhancing employment opportunities for people with disabilities.

In a recent study, governors of nine participating states voluntarily allowed the EEOC to review a wide range of best practices affecting individuals with disabilities who are state government employees or applicants for state employment. Examined were state government practices related to the following:

- $\quad$ the recruitment and hiring of people with disabilities for state jobs

- $\quad$ the provision of reasonable accommodations for applicants and employees with disabilities

- $\quad$ the retention and advancement of individuals with disabilities within the state government

- $\quad$ the employment of people with disabilities more generally - in both public and private sector jobs

Findings concerning state best practices aimed at recruiting and hiring qualified individuals with disabilities are encouraging. These include the establishment of training and hiring programs specifically for individuals with disabilities and also efforts to increase the number of qualified applicants with disabilities for jobs available to the general public. 
Based on information reported by the states, it appears that individuals involved in the hiring process have access to more than adequate training on subjects such as interviewing people with disabilities and preparing job descriptions. The job announcements examined do not describe jobs in a way that would inadvertently screen out qualified individuals with disabilities. Further, job announcements and job descriptions specifically reference the availability of reasonable accommodations for the application process and on the job.

The development and use of written procedures for providing reasonable accommodations, along with methods of documenting and tracking the disposition of requests and the provision of appeal processes following denials of reasonable accommodations, are also positive trends in some states. States that have not done so should consider the adoption of specific timelines for providing reasonable accommodations and use of centralized funding sources for the provision of more costly accommodations.

With respect to ensuring that individuals with disabilities are treated fairly once they are on the job, the states surveyed appear to offer significant ongoing training on the ADA and disability issues for managers and supervisors. Training on disability issues is increasingly becoming part of the states' diversity programs. However, there was little evidence of mentoring programs or training opportunities specifically aimed at promoting the advancement of employees with disabilities after they are hired or evidence that the states undertake any measures to determine the distribution of employees with disabilities among the various levels of the state government workforce.

Finally, the states surveyed have taken a significant number of steps aimed at increasing the employment of people with disabilities generally. This sends a clear message "from the top" that the employment of people with disabilities is a state priority.

In another study of large and small businesses, interviews with members of senior management, human resources staff, Directors of Diversity, and hiring managers were conducted. Three of the businesses have extensive experience employing people with disabilities (Aon Corporation, McDonald's, and Arrow Messenger) while the small business interviewed has negligible experience hiring people with disabilities (Data Armor). The goal of this study was to discover the reasons why businesses choose to employ people with disabilities and to learn how they successfully do it. Major findings are:

- $\quad$ The perceived benefits to hiring people with disabilities are the diverse perspective they provide and the loyalty they possess to the company that hires them. Other benefits include increased morale and the benefits that work provides to people with disabilities and society.

- $\quad$ Businesses employ people with disabilities due to certain commitments. This includes a strong commitment to diversity in general, a CEO with personal experiences with disabilities (Aon), strong relationships with the disability community, and an ethic of serving all sectors of the population (McDonald's), as well as a personal commitment to hiring people with disabilities, coupled with strong relationships with non-profit organizations that share the cost of accommodations (Arrow Messenger).

- $\quad$ The perceived barriers to hiring people with disabilities include attitudinal barriers, particularly among hiring managers, the fear of accommodation costs, and possible legal issues surrounding an employee with a disability.

- $\quad$ Smaller companies see employing people with disabilities as a larger risk than larger companies do. Small companies also see it as the role of larger companies to absorb the risk of employing people with disabilities. Smaller companies have other priorities, such as survival.

\section{CONCLUSION}

Based on the research and studies sited, it is clear that employers play a critical role in addressing the high unemployment rate experienced by persons with disabilities. Positive attitudes and practices are being implemented. However, more outreach, education, and awareness is necessary. Prior experience with workers with disabilities tends to produce more favorable perceptions and a willingness to hire people with disabilities. Many business executives believe that more should be done in their company and in others to integrate people with disabilities into the workforce (McFarlin et al., 1991). 
There has not been a time in history where emerging technology and progressive disability-related legislation coexisted to generate the most promising employment outlook for people with disabilities. Today, employers are increasingly faced with managing a diverse workforce, and many have strengthened their efforts in the area of corporate social responsibility. Diversity and social responsibility is inclusive of all people. It is time that people with disabilities are represented as part of the diversity and social responsibility strategies of organizations large and small. Including people with disabilities in this dynamic and most accommodating time frame will begin to change the fabric of the work force for the betterment of the country and the world.

\section{AUTHOR INFORMATION}

Nancy A. Maier, University of Detroit Mercy, College of Business Administration. E-mail: maierna1@udmercy.edu

Dr. Gregory W. Ulferts is a Professor of Decision and Systems Sciences in the College of Business Administration at the University of Detroit Mercy. His scholarly activities have included research and publication on various topics related to management information systems, financial management, decision sciences, small business administration, and international business. Dr. Ulferts has served as a consultant in business and government in areas such as strategic and technology planning, operations and procurement management, analysis and design of systems, and business development. E-mail: ulfertgw@udmercy.edu (Corresponding author)

Mr. Terry L. Howard is an Adjunct Professor of Information Systems and Technology in the College of Business Administration at the University of Detroit Mercy and works with the Business Leadership Network of Michigan and serves as the Director of the Leadership and Economic Independence program. Mr. Howard has MBA/MSCIS degrees from the University of Detroit Mercy and has certification in Security Information. He is a member of the National Honor Society, Alpha Iota Delta. Mr. Howard is a motivational speaker and has spoken to local organizations and to national groups. He has published papers nationally in professional and academic journals. E-mail: howardtl@udmercy.edu

\section{REFERENCES}

1. 2000 Census

2. 2010 Census

3. Boni-Saenz, Alexander A., Heinemann, Allen W., Crown, Deborah S., \& Emanuel, Linda L., The Business of Employing People with Disabilities: Four Case Studies Multi-Case Study Report grant (10-P-98360-5-

047) from the U.S. Social Security Administration (SSA) funded as part of the Disability Research Institute.

4. Final Report on Best Practices For the Employment of People with Disabilities In State Government The US Equal Employment Opportunity Commission, www.eeoc.gov/facts/final_states best_practices_report.pdf

5. Gibson, D., \& Groeneweg, G. (1986). Employer receptivity to the developmentally handicapped: When "yes" means "no." Canada's Mental Health, 34(2), 12-16.

6. $\quad$ Lengnick-Hall, Mark L., Gaunt, Philip M., \& Brooks, Adrienne A. R., 2001 Why Employers Don’t Hire People with Disabilities: A survey of the Literature

7. Unger, Darlene D. Employers' attitudes toward persons with disabilities in the workforce: myths or realities?. Focus on Autism and Other Developmental Disabilities Volume 17, Number 1, Spring 2002 Copyright $\odot$ PRO-ED, Inc. 